\title{
Rising to the Challenge: Nursing Leadership via Nurse-Led Service Provision for Chronic Disease Management and Prevention
}

\author{
Gary E Day ${ }^{1, *}$, Sharon Brownie ${ }^{1,2,3}$ \\ ${ }^{1}$ School of Nursing and Midwifery, Griffith University, 4222, Gold Coast, Australia \\ ${ }^{2}$ Oxford Praxis Forum, Green Templeton College, Oxford University, OX2 6HG, UK \\ ${ }^{3}$ Faculty of Health Sciences, University of Queensland, 4072, Australia \\ *Corresponding Author: g.day@griffith.edu.au
}

Copyright (C) 2014 Horizon Research Publishing All rights reserved.

\begin{abstract}
All nations are currently challenged by the increasing prevalence of non-communicable and chronic disease [1]. In Australia, by 2051, over $50 \%$ of the population over 50 will have a chronic disease [2]. In addition to increased levels of chronic disease, services will be stretched through workforce shortages, and government policies to provide greater access to services. Within the United States of America demand for primary care services will further increased by the passage and progressive implementation of the Affordable Care Act (ACA), which expands Medicaid coverage to millions of low-income Americans [3]. Given the increasing levels of disease burden, all staff, not just doctors, need to be viewed as part of the solution and encouraged to innovate and search for better and more affordable ways of delivering effective and appropriate care [4]. Globally, nurses are the largest and most accessible cohort within the health workforce. It is not surprising; therefore, that increasing reference to nurse-led services is present within the literature. This paper reports the findings of a focused literature review aimed at identifying the range of leadership skills and attributes required of nurses involved in the leading roles in the provision of nurse-led services and the management of nurse-led clinics. The implications for nursing education are highlighted and discussed.
\end{abstract}

Keywords Nurse-Led Clinics, Leadership, Health Workforce, Chronic Disease, Nurse Practice

\section{Introduction}

Nurses have played an important support role in the provision of primary health care in across the globe. However with the increase in the burden of disease through chronic illness and workforce shortages and substitution, nurses will need to play a more active and pivotal role in service provision in the decades ahead. The future burden of disease and the pressure this will put on health systems is stark. It is estimated that over three-quarters of the global burden of disease by 2020 will be chronic disease, with over $60 \%$ from cardiovascular disease and Type 2 diabetes [5]. Furthermore, projections suggest that in Australia by 2051, over $50 \%$ of the population over 50 will have a chronic disease [2].

Additionally, the literature reports that worldwide obesity has doubled since 1980. In 2008, there were over 1.4 billion people over the age of 20 classified as overweight, with 500 million of these classified as obese. Obesity raises the risk factors of chronic diseases such as cardiovascular disease and stroke and diabetes [6].

Adding to the growing primary health care service requirement that the increased chronic disease will need, medical services are struggling to meet this demand. In Australia, the medical workforce projections for General Practitioners will be unable to meet the growing demand of chronic disease [7]. Similarly, the Australian Institute of Health and Welfare [8, p498] reported that in 2010, 24\% of General Practitioner workforce was over 55. The over 55-year age group is expected to be a growing percentage of the medical workforce over the next decade. In Australia, sufficient medical practitioner numbers are threatened by increasing feminisation of the workforce, medical globalization and increased consumer demand [9]. The general practice workforce is likely to face continued chronic shortages and this will put pressure on the community's expectation for accessible primary health care [10]. In countries such as the United Kingdom, service provision gaps have appeared that are being filled by nurse-led services in part due to 'the roll out of the European Working Time Directive, limiting the number of hours doctors can work to 48 hours each week.' [11,p32].

Changes to health policy is also having an impact on the ability to service the chronic disease needs of the community. The introduction of the Affordable Care Act in the United 
States will see an additional 32 million low and middle income people being covered by health insurance [12]. A large percentage of these patients will be requiring primary health care services in an already stretched health care system.

These estimates of future largely preventable disease presents a challenge to conventional approaches to primary health care in terms of patient expectations, access to services and adequate suitably qualified staff to service this growing health need. These factors have seen the emergence of nurse-led services in primary health care.

\section{Rise of the Nurse-led Service}

Nurse-led services are finding currency in a range of primary care settings due in part to the perfect storm of an increased burden of chronic disease and chronic medical workforce shortages, particularly General Practitioners. Current research argues it is possible to extend the scope of the practice nurse to lead routine clinical management of patients with stable chronic disease [13]. In part, nurse-led services are increasing in legitimacy due positive clinical outcomes and cost effective approaches to patient care.

Dean [14, p.8] found nurse-led care of patients with respiratory disorders reduces Accident and Emergency admission, and in 'several specialties, such as diabetes and epilepsy, nurse-led services were found to be at least cost-effective as those provided by doctors.' Similarly, nurse-led services that delivered lifestyle interventions were effective in reducing risk factors associated with obesity, including weight, blood pressure, cholesterol, dietary and physical activity behaviors [15].

Research into nurse-led care in Australia, showed that nurses provide chronic disease management that is acceptable, feasible and sustainable [16]. Internationally, nurse-led services are proving to be successful alternative approaches to patient care rather than medical-led models. In Thailand, nurse led programs improved satisfaction and decreased symptom development in people with chronic diseases [17]. In the United Kingdom, nurse-led services have benefits beyond direct patient improvements, with nurse-led services having broader benefit to hospitals, GP services and Health Care Trusts in terms of efficiency [18].

With chronic disease placing an increased demand on primary health services coupled with medical workforce challenges worldwide, the literature has shown that nurse-led primary health services offers an effective clinical option for many communities. Delamaire and Lafortune [19, p. 43] argue that 'advanced practice nurses in different countries can provide equivalent quality of care when compared with that provided by doctors for certain patient groups in primary care and in chronic disease management...'

\section{Leadership Attributes}

While it is evident that nurses will require a range of advanced clinical skills to successfully manage the range of activities required within a nurse-led service, there are a range of professional and leadership skills that will be as critical if nurse-led services are to be successful.

Education providers need to increased education and training for nurses emphasising clinical skill development to improve patient outcomes [18]. Developing the technical and clinical skills to effectively manage nurse-led services is an essential component of managing safe, quality primary care services. However, clinical skills will not be enough to ensure sustainable models for nurse-led services. Nurses working in nurse-led services require a range of leadership skills to complement their clinical expertise if they are to remain relevant as front line service providers. There is a real need for strong leadership to ensure success of primary health care nurse-led clinics [20].

To focus the leadership requirements of nurses involved in leading primary care services, a leadership framework provides a useful starting point to highlight the important leadership attributes that will be essential if nurses are to successfully lead clinical services in primary health care. For the purposes of understanding the range of leadership attributes that are essential in the leadership of clinical services, the Health Workforce Australia (HWA) LEADS framework will be used. The Framework provides a usable structure for nurses to develop a range of attributes to support their approach to leading primary health services [21]. The framework provides five distinct but interconnected leadership areas for development, namely Leading Self, Engaging Others, Achieving Outcomes, Driving Innovation and Shaping Systems. These five key leadership areas are as important for nurses leading services in the acute sector as they are for primary health care.

\section{Leading Self}

Leading one's self incorporates the attributes of:

- Self Development;

- Self Awareness;

- Strength of character - integrity and resilience.

To be successful in leading clinical services, nurses will need to continually develop professionally and personally; understand the impact of their practice on those around them and high levels of integrity, ethical conduct and decision making. To improve clinical service provision, nursing staff need to develop strong levels of ethical conduct and decision making in line with consumer expectations [22]. Nurses also need to develop heightened levels of self awareness to ensure they understand the impact they are having on colleagues, other health professionals and the communities they work in. Self awareness and emotional intelligence are strong predictors of leadership potential [23].

\section{Engaging Others}

Engaging other clinical staff and consumers is critical to 
ensure successful program outcomes. Specific leadership traits in Engaging Others include:

- Values diversity and cultural responsiveness;

- Honest communication;

- Strengthens consumers, colleagues and other by inspiring them to share ideas and information.

The literature clearly demonstrates the importance of communication in not only engaging others but maintaining high levels of workplace and personal morale [24, 25], with communication being essential for the implementation and sustainable of nurse-led services [26].

\section{Achieves Outcomes}

Central to successful program delivery is achieving the desired or agreed outcomes. One of the important attributes is to be able to lead a team in achieving the agreed program outcomes. The specific traits identified are being associated with the HWA LEADS Framework includes:

- Influences and communicates the direction;

- Focused and goal oriented;

- Evaluates progress and is accountable for results.

As has been identified in other leadership traits in the HWA LEADS Framework, communication is central to influencing others to achieve the program goals as well as holding others to account for the agreed program outcomes.

Castledine [27, p1115] argues that formal evaluation is essential because nurse-led services 'disappear because of a lack of evidence as to their value and worth.' The investment required to implement primary health care programs effectively 'demands that processes and outcomes are evaluated, measured and reported, to identify their efficacy and acceptability.'[20, p21].

\section{Drives Innovation}

Managing the growing number of consumers requiring clinical interventions for their chronic disease management will require innovative approached to nurse-led services and the ability for the nurse leader to successfully manage the change proves. The three attributes for Driving Innovation include:

- Builds support for change;

- Champions the need for innovation and change;

- Positively contributes to spreading innovation practice.

Nurses that lead clinical services will need to lead the change process through other staff and champion the need for new approaches to clinical service provision.

\section{Shaping Systems}

Nurses that lead clinical services will need to develop strong professional partnerships and alliances with other clinicians, community groups and stakeholders to ensure the success of primary health care initiatives. The attributes nurses will need to develop to help shape the health system of the future includes:

- Understands and applies system thinking;

- Engages and partners with communities and consumers;

- Builds alliances.

Engagement and relationship building across professional and community boundaries are essential for successful service implementation and sustainability. Nurses will need to develop leadership based on strong relationships with other clinical and community groups rather than those based on clinical expertise. What will be important for nurses is to develop relational-based leadership characteristics and approaches rather than those that isolate nurses into clinical or program silos [28].

\section{Implications for Nursing Education and Professional Development}

While it is imperative that nurses develop and maintain advanced clinical skills to ensure safe, quality patient care, nurses cannot forget the importance of developing requisite leadership skills or risk nurse-led services becoming irrelevant or marginalised.

The University sector is well placed to imbed leadership and management content into undergraduate and postgraduate clinical courses. Nurses require a blend of clinical and non-clinical content that enable graduate and post graduate nurses to appreciate not only the clinical and care skills required but also the ability to successfully communicate and negotiate across clinical groups, managing change in a systematic way, evaluating service outcomes for efficiency and effectiveness, developing and implementing ethical decision making processes, demonstrating self aware as a clinician and being accountable for the results of the service.

Embedding leadership and management content within nursing degree programs does not absolve nurses from continuing their professional development outside of the confines of a university program. Ongoing relevance and sustainability of nurse-led programs is contingent upon nurses continuing to seek out development opportunities then testing and refining them in practice. Nurses need to move away from historical notions of "heroic" leadership models and embrace more relational-based leadership development that emphasises working collaboratively with other health professionals and consumers using a largely disseminated leadership approach [28]. In doing so, nurses bridge the gap between the traditional medical model of health care and engage consumers more constructively in a partnership based on community need and primary health care.

\section{Conclusion}

This paper has shown that nurses can be effective in 
leading a number of primary care services with an emphasis on chronic disease management. With predictions that chronic disease will place increased pressure on the health system at the same time there is a looming shortage of medical practitioners calls for new approaches to meeting the growing consumer demand.

Nurses are perfectly placed to offer alternative safe, effective and efficient service models into the future in both developed and developing countries. Sustainability and credibility of these services will be as much about clinical competence as it will be about effective leadership of these services. Successful leadership of nurse-run clinical services can provide a cost-effective alternative to the current medically-focused models and provide answers to addressing the future demand for chronic disease management services in primary health care settings.

\section{REFERENCES}

[1] A. Alwan, Global Status Report on Non-Communicable Diseases 2010, World Health Organisation, 2011.

[2] Australian Bureau of Statistics, Population Projections Australia 2004-2101, Canberra, 2005.

[3] Medicaide.gov, Affordable Care Act 2010, Available at: http://www.medicaid.gov/affordablecareact/affordable-careact.html.

[4] E. Nolte, E., C. Knai, M., McKee, M (eds) Managing Chronic Conditions: Experience in Eight Countries, European Observatory on Health Systems and Policies, World Health Organisation, Copenhagen, 2008

[5] J.Mackay, G.Mensah, The Atlas of Heart Disease and Stroke, World Health Organisation, Geneva, 2004.

[6] World Health Organisation, Obesity and overweight. Fact sheet $\quad N^{\circ} 311, \quad 2013, \quad$ Available from:http://www.who.int/mediacentre/factsheets/fs311/en/

[7] Australian Medical Workforce Advisory Committee, The General Practice Workforce in Australia: Supply and Requirements to 2013. Australian Medical Workforce, 2005

[8] Australian Institute of Health and Welfare, Australia's Health 2012, Australia's health series no.13, Cat. no. AUS 156. Canberra, 2012.

[9] P.M. Brooks, H.M. Lapsle, D.B. Butt, Medical Workforce issues in Australia: "Tomorrow's Doctors-Too Few, Too Far", Medical Journal of Australia, Vol.179, No.4, 206-208, 2003.

[10] C.M. Joyce, J.J. McNeil, J. Stoelwinder, More Doctors, But Not Enough: Australian Medical Workforce Supply 2001-2012, Medical Journal of Australia, Vol.184, No.6, 441-446, 2006.

[11] B.Herron, Nurse-Led Services are Vital But in Need of Clear Guidelines, Irish Medical Times, Vol. 43, No. 50, 32, 2009.

[12] S.R. Collins, How the Affordable Care Act of 2010 Will Help Low-and-Moderate- Income Families, Available at:http://www.commonwealthfund.org/Blog/How-the-Afford
able-Care-Act-of-2010.aspx, 2013.

[13] D.S. Eley, E. Patterson, J. Young, P.P. Fahey, C.B. Del Mar, D.G. Hegney, R.L. Synnott, R. Mahomed, P.G. Baker, P.A. Scuffham, Outcomes and Opportunities: A Nurse-Led Model of Chronic Disease Management in Australian General Practice, Australian Journal of Primary Health, Vol.19, 150-158, 2013.

[14] E. Dean, Research Finds Nurse-Led Services Deliver Better Patient Outcomes. Nursing Standard, Vol. 24, No.28, 8.2010.

[15] G..M. Sargent, L.E. Forrest, R.M. Parker, Nurse Delivered Lifestyle Interventions in Primary Health Care to Treat Chronic Disease Risk Factors Associated With Obesity: A Systematic Review, International Association for the Study of Obesity, Vol. 13, 1148-1171, 2012.

[16] D.G.. Hegney, E. Patterson, D.S. Eley, R. Mahomed, J. Young, The Feasibility, Acceptability and Sustainability of Nurse-Led Chronic Disease Management in Australian General Practice: Perspectives or Key Stakeholders, International Journal of Nursing Practice, Vol. 19, 54-59. 2013.

[17] S.Sindhu, C.Pholpet, S.Putta pitukpol, Meeting the Challenges of Chronic Illness: A Nurse-Led Collaborative Community Care Program in Thailand, Collegian, Vol. 17, 93-99.2010.

[18] S. Frost, W. Daly, Nurse-Led Asthma Services for Children and Young People: A Survey of GP's Views, Paediatric Nursing, Vol.22, No.8, 32-36, 2010.

[19] M. Delamaire, M., G. Lafortune, Nurses in Advanced Roles: A Description and Evaluation of Experiences in 12 Developing Countries, OECD Health Working Papers, No 54, OECD Publishing, 2010.

[20] M.Chiarella, Discussion Paper: New and Emerging Nurse-Led Models of Primary Health Care, Australian Government National Health and Hospitals Reform Commission, Accessed

from:http://www.health.gov.au/internet/nhhrc/publishing.nsf /Content/16F7A93D8F578DB4CA2574D7001830E9/\$File/ New\%20and\%20emerging\%20nurse-led\%20models\%20of $\% 20$ primary\%20health\%20care\%20(M\%20Chiarella).pdf , 2008.

[21] Health Workforce Australia, Health LEADS Australia: the Australian Health Leadership Framework., Available at: https://www.hwa.gov.au/sites/uploads/Health-LEADS-Austr alia-A4-FINAL.pdf, 2013.

[22] L. Casali, G. E.Day, Treating an unhealthy organisational culture: the implications of the Bundaberg Hospital Inquiry for managerial ethical decision making, Australian Health Review, Vol.34, 73-79, 2010.

[23] M. Higgs, P. Aitken, An Exploration of the Relationship Between Emotional Intelligence and Leadership Potential, Journal of Managerial Psychology, Vol.18, No.8, 814-823,2008.

[24] G..E. Day, V. Minichiello, J. Madison, Nursing Morale: Predictive Variables Among a Sample of Registered Nurses in Australia, Journal of Nursing Management, Vol.15, 274-284, 2007.

[25] G..E. Day, V. Minichiello, J. Madison, Self-Reported Perceptions of Registered Nurses Working in Australian 
Hospitals, Journal of Nursing Management, Vol. 15, 403-413. 2007.

[26] T. Dellagiacoma, Eight Essential Factors For Successful Nurse-Led Services, Australian Nursing Journal, Vol.14, No.10, 28-31, 2007
[27] G.. Castledine, G., How to Run an Efficient and Safe Nurse-Led Service, British Journal of Nursing, Vol.13, No.18, $1115,2004$.

[28] L. Fulop, G. E.Day, From Leader to Leadership: Clinician Managers and Where to Next?, Australian Health Review, Vol.34, 344-351, 2010. 